\title{
PERAN MASJID BAGI GENERASI MILENIAL
}

\author{
Deni Darmawan ${ }^{1^{*}}$, Samsul Marlin ${ }^{2}$ \\ Universtias Pamulang \\ dosen01723@unpam.ac.id' \\ ${ }^{*}$ Korespondensi
}

Naskah diterima: 25 Februari 2020, direvisi: 28 April 2020, disetujui: 2 Juli 2020

\begin{abstract}
Abstrak
Di era revolusi industri 4.0 peran masjid belum bisa menarik minat para generasi milenial. Masjid hanya dijadikan tempat ibadah, belum dijadikan tempat yang nyaman, cozy, tempat nongkrong yang positif, tempat berdiskusi, tempat pemberdayaan kompetensi pemuda, kaderisasi dan kegiatan lainnya. Dewan kepengurusan masjid (DKM) harus berfikir ke depan, kegiatan terkoneksi dengan dunia digital. Kekakuan dalam memilih konten, baik ceramah, kegiatan majlis ta'lim harus kekinian. Hendaknya masjid punya kegiatan yang beragam dan menarik sehingga bisa menampung generasi milenial. Era milenial ditandai dengan cepatnya informasi, kecanggihan teknologi, transportasi dan komunikasi yang diperkuat oleh tatanan organisasi dan manajemen yang tangguh. Peran masjid bagi generasi milenial hendaknya setiap program dan kegiatan bisa di informasikan melalui media khususnya media sosial seperti facebook, instagram, twiter, youtube, website, aplikasi pelayanan masjid, dan sebagainya. Generasi milenial dekat dengan teknologi. Sering menggunakan gadget dan smarphone untuk mendapat informasi dan komunikasi. Untuk memenuhi dan menampung para milenial, masjid diharapkan bisa menjadi magnet dan penarik untuk generasi milenial agar bisa memakmurkan masjid. Diantara peran-peran itu adalah: DKM harus melek digital, membuat konten yang menarik, menata masjid lebih nyaman, mengembangkan system manajemen informasi, dan pelayanan publik lainnya

Kata Kunci : Peran masjid, Generasi milenial
\end{abstract}

\section{Abstrak}

In the era of the industrial revolution 4.0 the role of mosques has not been able to attract the interest of millennials. The mosque is only used as a place of worship, not a place that is comfortable, cozy, a positive hangout, a place for discussion, a place to empower youth competence, regeneration and other activities. The mosque management board (DKM) still thinks colonial, not yet digital literacy, the determination to choose content, whether lecturing, taklim or other activities. The mosque should have diverse and interesting activities so that it can accommodate millennials. The millennial era is characterized by rapid information, technological sophistication, transportation and communication that is strengthened by a strong organizational and management order. The role of the mosque for millennial generation should be that every program and activity can be informed through the media, especially social media such as Facebook, Instagram, Twitter, YouTube, websites, mosque service applications, and so on. Millennial generation is close to technology. Often uses gadgets and smartphones to get information and communication. To meet and accommodate the millennial, the mosque is expected to be a magnet and attractor for millennial generations in order to prosper the mosque. Among those roles are: DKM must 
be digital literate, make interesting content, organize mosques more comfortably, develop information management systems, and other public services. 


\section{PENDAHULUAN}

Masjid memiliki posisi dan fungsi paling stategis dalam Islam. Selain sebagai rumah ibadah, masjid juga sebagai kegiatan pendidikan, pengkaderan, pengembangan ekonomi umat Islam, pelayanan publik lainnya. Sebagaimana pada periode Rasulullah Saw., sarana yang pertama kali dibangun ketika Rasul hijrah sampai di Madinah yang pertama kali beliau bangun adalah masjid di Quba yang letaknya pada waktu itu dipinggir kota Madinah, sekitar tiga mil dari masjid Nabawi (Supardi \& Teuku Amiruddin, 2001:2). Dengan demikian, pembangunan masjid merupakan manifestasi keimanan pertama kali sebagai sarana dakwah umat Islam, jika masjid masih sepi dan belum makmus karena masjid merefleksikan keimanan umat di lingkungannya.

Masjid pada era Rasul bukan saja sebagai tempat ibadah. Namun disisi lain juga menjadi tempat berkumpulnya kaum muslimin, menjadi pusat informasi yang paling penting, menjadi tempat mengatur segalan urusan mereka, menjadi sumber ilmu pengetahuan, sumber bacaan, sumber peringatan, nasehat dan pengarahan. Masjid sama seperti madrasah, ia berfungsi mengajarkan pokok-pokok agama, bahasa, dan adab kepada anak- anak. Karena itu masjid berperan sangat penting dalam pembelajaran agama dan pengetahuan. (Syaikh (Fuhaim Musthafa, 2009:52).

Penampilan dan manajemen masjid dapat memberikan gambaran tentang hubungan masjid dengan kualitas sumber daya manusia di sekelilingnya, Manajemen masjid harus dilaksanakan sebagai pengalaman dan hubungan manusia dengan Allah Swt dan hubungan manusia dengan manusia lainnya. (Supardi dan Teuku Amiruddin, 2001:10). Masjid bisa difungsikan untuk meningkatkan kualitas sumber daya manusia, bukan hanya untuk berhubungan kepada tuhannya, tetapi hubungan kepada manusia dan manusia lainnya, agar kehidupan lebih baik dan masjid bisa memberikan kemanfaatan untuk manusia lainnya.

Dalam perjalanan sejarahnya masjid telah mengalami perkembangan yang pesat, baik dalam bentuk bangunan maupun fungsi dan perannya. Pada masa sekarang masjid perlu untuk difungsikan, diperluas jangkaua aktivitas dan pelayanannya serta ditangani dengan organisasi dan manajemen yang baik, tegasnya butuh kegiatan mengaktuliasikan fungsi dan peran masjid dengan memberi warna dan nafas modern (Siswanto, 2002:6-7) 
Namun dalam konteks era digital, masjid belum mempunyai posisi dan fungsi masjid dimanfaatkan secara maksimal. Pemerintah, lembagalembaga, organisasi-organisasi kemasjidan, serta forum kemasjidan lainnya, sudah berupaya untuk memaksimalkan fungsi dan memperluas jaringan masjid, namun upaya itu belum dapat terdistribusi secara luas. Diantara faktornya, karena pengurus DKM belum mempunyai SDM yang baik dalam penguasaan manajemen, belum melek digital, masih lemahnya sistem informasi masjid, dan penguasaan teknologi dalam menerapkan IT pada masjid dan lembaga keagamaan masih sangat terbatas.

$$
\text { Teknologi merupakan }
$$
penunjang dari peribadatan itu sendiri. Kemajuan teknologi yang berkembang pesat tidak dapat dibendung, perubahan-perubahan dan penemuanpenemuan yang terus terjadi memberikan dampak yang cukup besar bagi peradaban manusia. Para generasi milenial sangat akrab dengan teknologi atau gadget. Untuk mengetahui siapa generasi milenial diperlukan kajian dan literatur dari berbagai sumber yang merupakan pendapat beberapa peneliti berdasarkan rentang tahun kelahiran. Salah satu fenomena penting proes globalisasi telah melahirkan generasi gadget, istilah yang digunakan untuk menandai munculnya generasi milenial. Generasi gadget dalam kehidupannya selalu bersinggungan dengan peralatan yang mengandung unsur teknologi informasi. Sehingga segala peralatan tersebut menjadi bagian yang tak terpisahkan dari kehidupan mereka. Seolah-olah berbagai alat hightechnology telah menjadi bagian terpenting dalam kehidupan (Zuhal, 2000).

Generasi milenial jika tidak landasi nilai spiritual, moral dan agama, semua temuan yang mengagumkan itu telah pula digunakan manusia untuk mendukung selera nafsunya. Praktik ekonomi yang kapitalistik dan berjiwa predator, politik yang menghalalkan segala cara, peredaran narkoba, perdagangan manusia, pergaulan bebas, praktek LGBT, perusakan lingkungan dan sebagainya, nampak semamin canggih, karena di dukung oleh teknologi yang dilakukan manusia generasi milenial. Peran masjid yang optimal, yang mampu memberikan wadah kegiatan generasi milenial dengan memanfaatkan teknologi informasi dan komunikasi, diharapkan generasi milenial bisa mencintai masjid, rajin ke masjid dan menjadi hambahamba yang taat dan patuh kepada Allah Swt 


\section{METODE PENELITIAN}

Penelitian ini menggunakan kualitatif deskriptif. Tujuannya adalah untuk menganalisis sebuah fenomena secara empirik berdasarkan kondisi yang tejadi secara alamiah. Menurut Creswell (2010) bahwa penelitian deskriptif tidak menguji hoptesis tertentu, tetapi hanya memberikan penjelasan dan mengemukakan apa adanya variabel, gejala, situasi dan keadaan. Peneliti akan melihat sebuah fenomena dalam penelitian ini dan dijelaskan secara komprehensif dan berpengaruh terhadap segala perubahan yang terjadi.

\section{PEMBAHASAN}

DAN

HASIL

\section{PENELITIAN}

\section{Revitalisasi Peranan Masjid}

Revitalisasi adalah proses, cara dan perbuatan menghidupam kembali suatu hal yang sebelumnya kurang berdaya.

Revitalisasi upaya, proses, cara untuk menghidupkan atau menggiatkan kembali berbagai program kegiatan apapun. Membangkitkan kembali vitalitas. Jadi, revitalisasi merupakan upaya untuk memvitalkan kembali suatu kawasan atau bagian kota yang dulunya pernah hidup, akan tetapi kemudian mengalami kemunduran atau degredasi.

Masjid berasal dari bahasa arab sajada yang berarti tempat sujud atau tempat menyembah Allah Swt. Selain itum masjid sebagai tempat orang yang berkumpul dan melaksanakan shalat secara berjamaah dengan tujuan meningkatkan solidaritaas dan silaturahmi dikalangan kaum musliminm dan masjid pulalah tempat yang terbaik untuk melangsungkan shalat jumat. (Muhammad E. Ayub, 1997:1-2). Dalam artian ini masjid sebagai tempat ibadah serta meningkatkan silaturahmi dikalangan kaum muslimin.

$$
\text { Dalam Al-Quran, masjid }
$$
diungkap dalam dua sebutan. Pertama, "masjid", suatu sebutan yang langsung menunjuk kepada pengertian tempat peribadatan umat Islam yang sepandan dengan sebutan tempat-tempat peribadatan agama-agama lain (Qs. 22:40). Kedua kata "bayt" yang menunjukkan dua pengertian, pertama tempat tinggal sebagaimana rumah untuk manusia atau sarang untuk binatang dan kedua "bayt Allah". Adapun fungsi dan peran masjid adalah:

\section{Ibadah (Habluminnalah)}

Fungsi dan peran masjid yang pertama dan utama adalah sebagai tempat shalat. (Syahruddin Hanafie, 1988:348). Shalat memiliki makna “menghubungkan”, yaitu menghubungkan diri dengan shalat dan shalat bukan hanya berarti menyembah saja. Shalat itu boleh 
dilakukan dimana saja, karena seluruh bumi ini adalah masjid (tempat sujud), dengan ketentuan tempet tersebut haruslah suci dan bersih, akan tetapi masjid sebagai bangunan khusus rumah ibadah tetap sangat diperlukan. Masjid bukan saja sebagai tempat kegiatan ritual sosial saja, tetapi juga merupakan salah satu simbol terjelas dari eksistensi lslam.

2. Sosial Kemasyarakatan

\section{(Hablumminannas)}

Seiring dengan kemajuan zaman dan perubahan-perubahan yang sangat cepatnya, maka hal ini mempengaruhi suasana dan kondii masyarakat muslim. Termasuk perubahan dan pengembangan fungsi dan peranan masjid yang ada dilingkungan kita. Salah satu fungsi dan peran masjid yang masih penting untuk tetap dipertahankan hingga kini adalah dalam bidang sosial kemasyarakatan. Selain itu, masjid juga difungsikan sebagai tempat mengumumkan hal-hal yang penting berkaitan dengan peristiwaperistiwa sosial kemasyarakatan sekitar. (Sidi Gazalba, , 1872:127)

Masjid mempuyai posisi yang sangat vital dalam memberikan solusi bagi permasalahan sosial di masyarakat apabila benar-benar dijalankan sesuai dengan fungsinya. (Teuku Amiruddin, 2008:52). Fungsi masjid harus mempunyai programprogram dan kegiatan yang dibuat dan dirancang sebagai solusi bagi permasalahan sosial yang ada.

\section{Ekonomi}

Hubungan masjid dengan kegiatan ekonomi tidak hanya hubungan tempat mengkaji gagasangagasan tentang ekonomi saja, tetapi lingkunga tempat transaksi tindakan ekonomi pada khususnya disekitar masjid, seperti pinggiran masjid, halaman masjid. Ide-ide dasar prinsip Islam mengenai ekonomi berlaku dan dipraktikkan oleh umat Islam dari dulu hingga sekarang kini. Dulu masjid bisa melahirkan kompleks pertokoan, karena toko-toko dapat membantu kebutuhan masjid dan sarananya.

Aktivitas ekonomi tersebut merupakan kehendak dasar manusia atau kelompok masyarakat untuk memenuhi kebutuhan hidupnya yang tidak mungkin diperoleh secara mandiri.

Masjid sebagai Bait At-Tanwil, secara umum adalah mengembangkan usaha-usaha produktif dan investasi dalam meningkatkan kualitas kegiatan ekonomi pengusaha kecil dengan 
antar lain mendorong kegiatan menabung dan menunjang kegiatan ekonominya. (Kuat lsmanto, Jurnal Penelitian, 2015-24)

\section{Pendidikan}

Rasulullah dicatat oleh sejarawan sebagai orang berhasil melakukan dakwah di penjuru dunia. Salah satu keberhasilan dakwah tersebut adalah mengoptimalkan masid, salah satunya adalah bidang pendidikan. Masjid sebagai tempat pendidikan non-formal, juga membina dan mengkader manusia menjadi insan beriman, insan kamil, bertakwa, berilmu, beramal shaleh, berakhlak dan menjadi warga yang baik serta bertanggung jawab.

Untuk mengoptimalkan fungsi masjid dibidang pendidikan memerlukan waktu yang lama, sebab pendidikan merupakan proses yang berlanjut dan berulang-ulang. Pendidikan mempunyai peranan yang penting dalam meningkatkan kualitas jamaah dan menyiapkan genetrasi muda untuk meneruskan serta mengembangkan ajaran Islam, maka masjid sebagai media pendidikan massa terhadap jamaahnya perlu diperhatikan dan ditingkatkan. (Hanafie Syahruddin, 1988:350).

\section{Dakwah}

Dakwah secara bahasa adalah mengajak, menyeru dan memanggil. Secara etimologis dakwah merupakan proses menyampaikan (tabligh) pesan-pesan tertentu yang berupa ajakan atau seruan dengan tujuan agar orang lain memenuhi ajakan tersebut. Secara istilah yaitu mengajak manusia dengan cara bijaksana kepada jalan yang benar sesuai dengan perintah Tuhan, untuk kemaslahatan dan kebahagiaan mereka di dunia dan akhirat.

Masjid menjadi pusat dakwah yang menyelenggarakan kegiatankegiatan rutin seperti pengajian, ceramah-ceramah agama, kuliah shubuh dan kegiatan yang bermanfaat lainnya. Kegiatan ini sangat penting untuk menginternalisasi tentang nilai-nilai ditengah-tengah masyarakat secara luas atau ungkapan lain bahwa melalui kegiatan pengajian, sebenarnya masjid telah menjalankan fungsi sosial.

6. Politik

Secara terminologi politik adalah interaksi antara pemerintah dan masyarakat dalam rangka pembuatan an pelaksanaan keputusan yang mengingat tentang kebaikkan bersama masyarakat yang 
tinggal dalam suatu wilayah tertentu. Pada zaman Nabi, fungsi dan peran masjid sebagai tempat pemerintah, tempat diskusi-diskusi pemerintah dengan sahabat, diskusi siasat perang, perdamaiana dan sebagainya. Segala hal ihwal dunia selalu didiskusikan didalam masjid, untuk mengambil keputusan

\section{Kesehatan}

$$
\text { Masjid memberikan sarana }
$$
untuk pengobatan dan mengadakan kegiatan-kegiatan keolahragaan, seperti yang diajarkan oleh Rosulullah Saw. Sehat secara mental/psikis adalah sehat pikirannya, emosional, maupun spiritual dari seseorang. Seseorang dikatakan sehat secara sosial adalah kemampuan seseorang berinteaksi dengan lingkungan dimana ia tinggal. Sehat secara ekonomi adalah orang yang produktif, produktifitasnya mengantarkan ia untuk bekerja dan bekerja ia akan dapat menunjang kehidupan keluarga.

Pada zaman Nabi Saw., berfungsi sebagai balai pengobatan bagi seluruh pejuangan-pejuangan yang mengalami luka setelah berperang. Nabi juga memanfaarkan aktivitas untuk hal duniawi (hablumminnas). Jika masjid memiliki balai pengobatan seperti klinik, atau rumah sakit, maka masyarakat yang membutuhkan akan sangat tebantu dalam pengeobatannya dan masjid akan selalu ramai.

\section{Pelayanan Publik}

Masjid menjadi sentral pusat kegiatan kaum muslimin. Masjid sebagi Bait at-Takmim, artinya masjid memiliki kemampuan dalam memberikan jaminan sosial bagi jamaahnya. Pada masyarakat awal Islam, Nabi Muhammad Saw., memberikan tempat khusus bagi jamum suffah dan menjamin kehidupan mereka melalui peran masyarakat yang aktif di masjid. Masjid bisa sebagai tempat pelayanan konsultasi yang lebih luas, komunikasi, ruang diskusi sebelum dan sesudah sholat, pelayanan menyediakan perpustakaan berbagai buku bacaan dengan berbagai disiplin keilmuan program ini disebut l'tikam ilmiah.

\section{Generasi Milenial}

$$
\text { Milenial atau generasi } Y
$$

adalah generasi yang tumbuh pada era internet booming dimana generasi ini memiliki karakteristik masing-masing indvidu berbeda, hal tersebut tergantung dimana ia dibesarkan, strata ekonomi, dan social keluarganya, pola komunikainya sangat terbuka 
disbanding

generasi-generasi

sebelumnya, pemakai media social yang fanatic dan kehidupannya amat terpengaruh dengan teknologi, lebih terbuka dengan pandangan politik, dan ekonomi, sehingga mereka terlihat sangat reaktif terhadap perubahan lingkungan yang terjadi di sekelilingnya. Dengan memiliki ciri yang sangat mudah terpengaruh dengan perkembangan teknologi seringkali membuat generasi sangat cepat dalam mengakses berbagai informasi yang ada melalui media social yang mereka punya. (Dwiyun Evi Yoland, dkk, academia.edu)

Generasi ini lagir antara tahun 1981-2000, atau yang saat ini berusia 35-50 tahun. Generasi ini menjadikan teknologi informasi sebagai gaya hidup atau lifestyle. Generasi ini dengan ciri unik, teknologi yang melekat pada mereka sejak lahir. Ada kecenderungan mendidik generasi harus dengan pola tertentu, semisl system belajar longgar, jaih dari kekerasan, dengan metode partisipatoris.

Pada tahun ini, rata-rata dunia pendidikan, generasi yang paling banyak sedang menempuh jenjang perkuliahan adalah generasi milenial. Generasi ini menyukai sesuatu yang out of the box, sangat suka tantangan dan penghargaan. Mereka cenderung overconfidence, berani mengungkapkan pendapat, baik langsung ataupun melalui media social. Generasi ini tumbuh seiriing dengan munculnya berbagai terobosan baru dalam teknologi komunikasi dari mulai SMS, E-mail, Whatsapp, line, dan berbagai bentuk komunikasi tertulis lainnya. Generasi ini lebih menyukai semua bentuk komunikasi yang lebih bersahabat dan nada bicara yang lebih akrab.

\section{Peran Masjid Bagi Generasi Milenial}

Generasi milenial dekat dengan gadget, menghabiskan waktu di depan layar perangkat mobile sekitar tiga jam sehari, hingga terus meningkat penggunaan tersebut hingga menjadi 20 persen. Merea juga sebanyak 7 persen remaja berusia 16-19 tahun yang menonton video memalui youtube ketimbangan nonton TV. Waktu yang dialokasikan untuk menonton streaming juga meningkat tiga kali lipat. Fakta tersebut membuktikan, perilaku generasi milenial sudah tidak bisa dilepaskan dari menonton video secara daring. Melihat fenomena ini, bagaimana peran masjid bagi generasi milenial. Ada beberapa hal yang perlu diperhatikan adalah:

1. DKM menguasai teknologi

Dewan Kepengurusan Masjid (DKM) harus akrab dengan teknologi. Penggunaan teknologi 
upaya untuk meningkatkan peran dan fungsi masjid. Masjid dan teknologi merupakan dua hal yang berkaitan, masjid sebagai tempat ibadah, dan teknologi merupakan penunjang dari peribadatan itu sendiri. Kemajuan teknologi yang berkembang pesat tidak bisa dibendung, perubahan dan penemuan yang terjadi memberikan dampak yang cukup besar bagi peradaban manusia.

Misalnya penggunaan pengeras suara untuk azan. Suara azan dikumandangkan di masjid akan terdengar ke seantero kampung. Penggunaan CCTV merupakan upaya untuk meningkatkan dan kewaspadaan kejahatan, seperti pencurian mobil atau motor, pencurian kotak amal, sepatu, dan sebagainya. Pengurus di berikan pelatihan dan pengembangan seputar media informasi dan komunikasi agar bisa mengoperasionalkan, mengendalikan, dan memanfaat media sosial seperti fabebook, Instagram, yootube, twitter, web dan sebagainya, untuk bisa menginformasikan seluasluasnya kegiatan masjid sehingga generasi milenial akan memantau dan tertarik kegiatan dan program yang disajikan oleh DKM.

\section{Membuat program menarik}

DKM dalam memilih kegiatan dan program harus menarik dan sekreatif mungkin agar generasi milenial bisa menarik minat para milenial untuk rajin ke masjid. Materi yang disampaikan oleh para narasumber sangat mudah dicerna, santai tapi berbobot, terbuka dan tidak kaku. DKM juga bisa mengundang narasumber, bintang tamu, atau ustadz yang mewakili generasi milenial seperti Ust. Hanan Attaki, Ust. Abdul Somad, dan ustadz lainnya yang mempunyai banyak follower generasi milenial di youtube atau medsos lainnya. Dengan begitu, jika DKM mengundang ustad yang mempunyai banyak pengikut milenial, maka generasi milenial akan banyak yang ke masjid untuk taklim dimasjid. Tidak hanya itu, pengurus masjid bisa membuat program olah raga, program usaha, dan program yang menarik lainnya, tidak hanya program keagamaan saja.

\section{Menata layout Masjid}

Pekarangan masjid bisa dibangun kantin, warung kopi atau cafe sehingga milenial bisa rehat dan ngobrol santai. Menampilkan tatanan masjid yang nyaman, cozy dan menarik merupakan upaya 
agar masjid bisa disukai oleh generasi milenial. Sediakan buku baca, tersedia wifi, dan taman sehingga se-asri mungkin untuk bisa diskusi santai dan kelompok belajar. Menguatkan budaya literasi, dengan diskusi yang hangat, dengan begitu jauh dari pemahaman radikalisme. Sehingga masjid menjadi tempat menukar ide dan gagasan cemerlang dari para milenial.

\section{Pengembangan sistem manajemen} informasi

Masjid mampu mengembangkan system manajemen informasi berbasis kebutuhan masjid. Fungsi masjid bisa maksimal terutama untuk melayani kebutuhan informasi kegiatan dan program masjid, memperluas jaringan, sehingga para milenial bisa terus meng-up date dan memberdayakan para milenial dalam upaya memperkaya khazanah ke-lslaman, dan memperluas akses masjid secara global. (Nazarudin Musa, Jurnal masjid digital, hal: 2). Diantara manfaat lainnya adalah, memudahkan donator untuk memberikan donasi ke masjid, meningkatkan kuantitas informasi Islami di dunia maya, memiliki database kemasjidan sehingga memudahkan dalam pencarian data, masjid menjadi media pembelajaran bagi para milenial dan meningkatkan kreatifitaas dan kapasitas pengelola masjid dalam upaya mewujdukan pemanfaatan internet positif dan produktif.

\section{Pelayanan publik lainnya}

Masjid bisa menyelenggarakan pelayanan publik seperti konsultasi, kesehatan, lembaga atau kursus pendidikan, ekonomi syariah, seminar, pelatihan, workshop dan pelayanan lainnya. Dengan berbagai pelayanan publik yang yang ada, para milenial akan tertarik untuk mengikuti kegiatan di masjid.

\section{KESIMPULAN}

Masjid mempunyai peran amat penting dalam membangun peradaban. Peran masjid bukan saja sebagai tempat ibadah, tapi juga tempat pendidikan, pengkaderan, layanan publik, tempat diskusi, musyawarah, segala aspek dari ekonomi, politik, budaya dan sebagainya. Masji harus dioptimalkan perannya sehingga kemanfaatan akan terasa oleh masyarakat luas khususnya bagi generasi milenial.

Generasi milenial dekat dengan teknologi. Sering menggunakan gadget dan smarphone 
untuk mendapat informasi dan komunikasi. Untuk memenuhi dan menampung para milenial, masjid diharapkan bisa menjadi magnet dan penarik untuk generasi milenial agar bisa memakmurkan masjid. Diantara peran-peran itu adalah: DKM menguasai teknologi, membuat program yang menarik, menata layout masjid lebih nyaman, mengembangkan sistem manajemen informasi, dan pelayanan publik lainnya.

\section{DAFTAR PUSTAKA}

Supardi dan Teuku Amiruddin. 2001. Manajamen Masjid dalam Pembangunan Masyarakat Yogyakarta: Ull Press.

Syaikh Fuhaim Musthafa. 2009. Kurikulum Pendidikan Anak Muslim. Surabaya : Pustaka Elba, 2009.

Supardi dan Teuku Amiruddin. 2001. Manajamen Masjid dalam Pembangunan Masyarakat,

Siswanto. Panduan Pengelolaan Himpunan Jamaah Masjid. Jakarta : Pustaka Amani, 2002.

Mohammad, E. Ayub. Manajemen Masjid. Jakarta: Gema Insani, 1996

Hanafie, Syahruddin. Mimbar Masjid,Pedoman untuk para khatib dan pengurus masjid. Jakarta: Haji Masagung, 1988.
Sidi Gazalba. 1971. Masjid Pusat Ibadah dan Kebudayaan Islam. Jakarta: Pustaka Antara

Teuku Amiruddin. 2008. Masjid Dalam Pembangunan. Yogyakarta: Ull

$$
\text { Kuat Ismanto. "Pengelolaan }
$$
Baitul Maal pada Baitul Maal Wa Tanwil (BMT) Di Kota Pekalongan," Jurnal Penelitian, 1 (Mei 2015).

Cresswell, J. W. 2010. Research design; Pendekatan Kualitatif, Kuantitatid dan Mixed. Yogyakarta: Pustaka Belajar. 

(KAHPI)

p-ISSN 2685-8401 e-ISSN 2685-7502 